\title{
Study Abroad and Intercultural Development: A Longitudinal Study
}

\author{
Rich a rd J. Rexeise n \\ University of St. Thomas \\ Philip H. Anderson \\ University of St. Thomas
}

Leigh L a w ton

University of St. Thomas

\author{
Ann C. H ub bard \\ University of St. Thomas
}

\section{Introduction}

Study abroad is an expensive, resource intensive activity for both students and their home institution. With an estimated 200,000 American students studying abroad in 2006, and an annual growth rate of eight percent (Institute for International Education, 2006), program administrators and international scholars are increasingly being asked to document the learning outcomes associated with study aboard to validate the expenditure of funds and resources (Vande Berg, 2001). Accrediting bodies such as Accrediting bodies such as The Higher Learning Commission (2007) and the Association to Advance Collegiate Schools of Business (2007) are also calling upon colleges and universities to formally assess the extent to which they are preparing their students to live and work in an increasingly interdependent global community.

While academic units often express a wide range of learning goals and objectives within the context of international study, the importance of intercultural development is recognized by virtually all institutions (Greenholtz, 2000; Hammer, Bennett and Wiseman, 2003). Broadly conceived, intercultural sensitivity helps people to live and work with people of diverse cultural backgrounds (Landis and Bhagat, 1996) and this in turn contributes to building essential leadership skills necessary for operating effectively in an increasingly complex global environment (Earnest, 2003). Tensions created as a consequence of the global war on terror have also drawn attention to the strategic value and overall importance of developing essential intercultural skills (Lincoln Commission, 2005). 


\section{Literature Review Measuring Intercultural Development}

Many approaches to measuring intercultural competency have been proposed over the years. Kelley \& Meyers' (1995) Cross Cultural Adaptability Inventory (CCAI) has been widely used to assess an individual's effectiveness in intercultural interaction and communication. The Intercultural Adjustment Potential Scale (ICAPS) helps identify elements of a study abroad experience that contribute to intercultural adjustment (Savicki et. al., 2004). The International Education Survey (IES) has been used to assess how an international experience impacts personal and intellectual development (DeDee and Stewart, 2003). The Global Awareness Profile (GAP) assesses the degree to which a person can recognize and appreciate the size, complexity and diversity of intercultural experiences and thereby be able to form an integrated worldview (Corbitt, 1998). The Beliefs, Events and Values inventory (BEVI) is based on the level of agreement with various belief-value statements and assesses a number of characteristics related to intercultural competency, e.g., openness, tendency to stereotype, receptivity, etc. (Shealy, 2005). The BEVI instrument is in the final stages of trial validation. The Intercultural Development Inventory (IDI) by Hammer and Bennett (2002) measures the respondent's overall development of intercultural sensitivity based on an individual's progression through six stages of cultural development.

We chose to use Hammer \& Bennett's Intercultural Development Inventory (2002) for four reasons. First, the IDI was designed specifically to measure intercultural development, which is the focus of this study. Second, the IDI is grounded in theory (Bennett 1986, 1993). Davis and Finney (2006) argue that a solid theoretical base offers opportunities for further testing and development and may allow researchers to generalize results even when non-probability samples are used; a common problem when assessing study abroad programs. Third, the IDI has been subjected to extensive psychometric testing (Hammer, Bennett, and Wiseman, 2003; Paige et. al., 2003). As noted by Davis and Finney (2006, pg., 328), “... if an instrument being used has poor psychometric properties, the inferences made based on those findings are at best ambiguous." And finally, we chose the IDI for the current study because it is both a descriptive and normative tool; it helps explain why people respond differently to different cultural experiences. It is our long-term desire to develop intervention strategies that can be used to improve the overall quality of our institution's study abroad programs. Paige (2004) suggests that the IDI is useful for guiding the development of training modules and other intervention strategies; all 
with minimal participant resistance. Paige concludes that overall the IDI is an effective instrument to integrate into intercultural training programs.

The IDI was developed and refined by Hammer and Bennett (2002) to measure an individual's stage of intercultural development using a model developed by Bennett $(1986,1993)$. Bennett's Developmental Model of Intercultural Sensitivity (DMIS) is based on research showing that people progress through distinct and predictable stages of intercultural development as they experience cultural differences in progressively more complex ways (Hammer and Bennett, 2002; Hammer et al., 2003; Klak and Martin, 2003). These stages range from denial and defense through integration. The IDI is consistent with Bhawuk and Brislin's (1992) description of intercultural sensitivity as an individual's reaction to people from other cultures develops and changes over time.

The IDI measures an individual's overall stage of development in addition to providing various scales that approximate Bennett's stages of intercultural development. The first stages of development (Denial/Defense, Reversal, and Minimization) represent an ethnocentric perspective whereas the latter stages (Acceptance/Adaptation and Encapsulated Marginality) represent the degree to which a person has developed an ethnorelative perspective. For example, the underlying construct that Hammer and Bennett label as "defense against differences" is properly understood to be a more-or-less rigid judgment that one culture is superior to another. Defensive characteristics generally take the form of "my culture (way of doing things) is superior to all others" or "if only other people in the world understood my culture, then they too would want to do things the way we do." A related version of this trait, known as reversal, occurs when people come to judge other cultures as superior to their own. (For a full description of the IDI scales, see www.intercultural.org/idi_dmis.php.)

\section{The Impact of Study Abroad Programs}

While there have been increasing pressures to document the impact of study abroad programs, few studies have employed pre-post measures in an attempt to measure changes. Medina-López-Portillo (2004), Engle and Engle (2004), and Paige, Cohen, and Shively (2004) have examined intercultural sensitivity in study abroad programs designed to improve language skills. Paige et al. (2004) found that US students studying language in French and Spanish speaking countries improved overall intercultural sensitivity and Engle and Engle (2004) reported similar findings. Engle and Engle also observed that students involved in longer-term programs (full year versus one semester) showed the greatest gain in intercultural sensitivity. By contrast Medina-Lopéz-Portillo 
(2004) found little evidence for improvement as the result of a seven-week or semester-long program of study in Mexico.

Short-term programs (one month or less) have also been shown to have an impact on intercultural development. Anderson, Lawton, Rexeisen and Hubbard (2006) for example report a positive impact on intercultural sensitivity for a short-term (four-week) non-language-based study abroad program. Patterson (2006) compared the effects of a short-term (two to four week) study abroad experience with that of on-campus intercultural study. Patterson found that there was a small improvement in intercultural sensitivity for those that studied abroad and no improvement for those with the traditional classroom experience.

While additional studies employing a pre-post design are needed to evaluate the effect of study abroad programs, there is little research to show that study abroad has a lasting impact after students return to their home culture. A notable exception is a 2002 survey conducted by The Institute for the International Education of Students (IES, 2002), one of the largest known surveys of study abroad alumni. The survey resulted in more than 3,400 returned questionnaires yielding an overall response rate of $23 \%$. The students overwhelmingly reported that they continued to develop their self-confidence and world-view after returning home as a result of their study abroad experience. An important limitation of the IES survey is that its findings are based on the alumni's subjective self-report. This current study will address this shortcoming by assessing whether or not improvement continues four months after returning from study abroad as measured by the IDI.

The current study also assessed whether academic ability as measured by GPA scores or gender are related to changes in intercultural development as the result of a study abroad experience. Rexeisen and Roffler (2005), for example, report that gender is related to changes in environmental attitudes as a result of a semester study abroad. They found that the ecological worldview of women, as measured by the New Ecological Paradigm, tended to improve whereas men's attitudes tended to decline as a result of their study abroad experience. A review of study abroad programs reveals that GPA is a common screening criterion used for students studying abroad. Consequently, we evaluated whether there is a relationship between academic ability (as measured by cumulative GPA) and intercultural development. Given the propensity for academic aptitude to be related to many different measures of student achievement, this study predicts that cumulative GPA will be positively related to changes in intercultural development. 


\section{Research Hypotheses}

Van Hoof and Verbeeter (2005) report that students believe study abroad enriches them personally in ways that would not be possible studying at their home institution. This observation is consistent with the personal experiences of the researchers who collectively have led 17 study abroad programs over the past 12 years. The question is whether it can be demonstrated empirically that study abroad programs improve intercultural sensitivity. To address this question, the following hypotheses are tested in the current study:

\section{Pre-test vs. Post-test Hypotheses}

Hypothesis 1a: A semester long, faculty-led study abroad program will have a positive impact on the overall development of intercultural sensitivity as measured at the conclusion of the semester pre-test to post-test

Hypothesis 2a: There will be a reduction of denial and defense characteristics of participants from pre-test to post-test.

Hypothesis 3a: There will be a reduction of reversal tendencies or the propensity to see other cultures as superior to one's own from pre-test to post-test.

Hypothesis 4a: There will be a reduction in the degree of minimization of cultural differences from pre-test to post-test.

Hypothesis 5a: There will be an increase in the degree of acceptance of and adaptation to cultural differences from pre-test to post-test.

\section{Post-test vs. Follow-up Hypotheses}

Hypothesis 1b: Overall intercultural development will continue to improve after returning from the study abroad program (post-test to follow-up).

Hypothesis $2 \mathrm{~b}$ : There will be a further reduction of denial and defense characteristics of participants from post-test to follow-up.

Hypothesis 3b: There will be a further reduction of reversal tendencies or the propensity to see other cultures as superior to one's own from post-test to follow-up.

Hypothesis 4b: There will be a further reduction in the degree of minimization of cultural differences from post-test to follow-up.

Hypothesis 5b: There will be a further increase in the degree of acceptance of and adaptation to cultural differences from post-test to follow-up. 


\section{Gender \& GPA Comparisons}

Hypothesis 6: There will be gender differences related to intercultural development.

Hypothesis 7: A student's academic aptitude (as measured by cumulative GPA) will be positively related to intercultural development in both pre-test to post-test and post -test to follow-up.

\section{Met hodology}

\section{The Subjects}

The subjects in this research were traditional, college-aged students at a medium-sized, private Midwestern university in the United States. The undergraduate student body consists of less than $10 \%$ international students or students of color. The sample consisted of 54 junior-level students majoring in business participating in a semester-long study abroad program in London, England. The average age was 21 years and $60 \%$ were women. Approximately half of the sample reported that they had traveled for less than 10 days outside of the United States prior to the current study abroad experience; $34 \%$ reported between 10 days and a month; and $17 \%$ indicated that they had traveled or lived for more than a month outside the US. The average GPA of the group was 3.5 with a range of 3.0 to 3.9. Eighty-nine students applied for the London program and only 54 were selected. Students were selected based on GPA, student essays, letters of recommendation and personal interviews.

\section{The Study Abroad Program}

The program was led by two faculty members from the home institution. Classroom instruction was conducted by the US faculty members as well as by British instructors. Classes met during the day, leaving evenings for the students to explore the local surroundings. In addition to their classroom duties, the US faculty served as academic advisors, counselors, and overseers of a service learning project in which the students participated as part of the study abroad program. For the service learning project, the students worked with a number of non-profit organizations in the British community.

While in London, the students' accommodations were with British families. Student involvement with the families varied considerably but often included shared meals and conversations regarding British life. The program also included day trips to sites such as Oxford and Bath. In addition, the students traveled on weekends to various European locations providing additional opportunity to observe and experience intercultural differences. 


\section{The Study}

The IDI was first administered at the beginning of the semester prior to departure from the U.S. The second administration of the IDI occurred at the end of the term but prior to returning to the U.S. A final administration occurred four months later, after the students had returned to the U.S. Collection of the data and analysis of results were conducted under supervision of faculty trained and certified by the Intercultural Communication Institute.

\section{Res u I t s}

Forty-eight students out of $54(89 \%)$ enrolled in the semester abroad program completed the pre-test IDI survey. Forty-six students completed the IDI at the end of the semester and 39 students (81\%) of the original 48 students completed the pre-test, the post-test, and the final follow-up study four months after the end of the study abroad program. The responses for these 39 students were used to test the hypotheses in this study.

\section{Pre-test vs. Post-test Hypothesis Results}

As predicted, the students as a group exhibited a significant $(\mathrm{p}=.007)$ gain in their Overall Development score by the end of their semester study abroad program providing strong support for Hypothesis 1a (Table 1). The average score increased from 88.3 to 93.3. While significant progress was observed, the group mean for the students remained overall within the Minimization category range of 85-114 (Table 1).

Table 1. Paired One-tailed t-tests of Pre-test vs. Post-test Results

\begin{tabular}{|l|l|l|l|l|l|l|l|}
\hline & \multicolumn{3}{|l|}{ Pre-test Results } & \multicolumn{3}{l|}{ Post-test Results } & \\
\hline Hypothesis & Ave. & Range & S.D. & Ave. & Range & S.D. & $\begin{array}{l}\text { p- } \\
\text { value }\end{array}$ \\
\hline $\begin{array}{l}\text { H1a - Overall } \\
\text { Development }\end{array}$ & 88.3 & $\begin{array}{l}58- \\
126\end{array}$ & 15.4 & 93.3 & $\begin{array}{l}72- \\
129\end{array}$ & 15.9 & .007 \\
\hline $\begin{array}{l}\text { H2a - } \\
\text { Defense/ } \\
\text { Denial }\end{array}$ & 4.12 & $\begin{array}{l}2.8- \\
5.0\end{array}$ & .55 & 4.06 & $2.9-$ & .56 & .794 \\
\hline $\begin{array}{l}\text { H3a - } \\
\text { Reversal }\end{array}$ & 3.50 & $\begin{array}{l}2.1- \\
5.0\end{array}$ & .742 & 3.71 & $\begin{array}{l}2.7- \\
5.0\end{array}$ & .65 & \\
\hline $\begin{array}{l}\text { H4a - } \\
\text { Minimization }\end{array}$ & 2.62 & $\begin{array}{l}1.8- \\
4.0\end{array}$ & .63 & 2.83 & $\begin{array}{l}1.7- \\
4.3\end{array}$ & .68 & .033 \\
\hline $\begin{array}{l}\text { H5a - } \\
\text { Acceptance/ } \\
\text { Adaptation }\end{array}$ & 3.17 & $\begin{array}{l}1.8- \\
4.5\end{array}$ & .66 & 3.48 & $\begin{array}{l}2.4- \\
4.5\end{array}$ & .53 & .001 \\
\hline
\end{tabular}


In an effort to better understand the intercultural changes that occurred during the study abroad experience, we also assessed the changes in the composite scales that make up the overall IDI developmental score. Since none of the students in the study reached the Encapsulated Marginality stage (130+) in their Overall Development score, we did not conduct a pre-post analysis for this scale.

Table 1 shows that there was no significant improvement in the students' score on the Defense/Denial scale. Although we hypothesized that we would find a reduction in the students' Defense/Denial characteristics (Hypothesis 2a), the results were not surprising since most of the students had been fairly successful in resolving denial and defense issues prior to their study abroad (as reflected by the average score of 4.12 on a scale of 5 , with a standard deviation of .55).

As predicted there were significant improvements in the student scores on the Reversal, Minimization and Acceptance/Adaptation scales, supporting Hypotheses 3a, 4a, and 5a. These results show broad support for the students' intercultural development as a consequence of their study abroad. It should be noted however that post-test averages for these scales $(3.71,2.83$, and 3.48 respectively) show that the students still have not as a group fully resolved these issues.

\section{Post-test vs. Follow-up Hypothesis Results}

Table 2 shows the results for the analysis of the post-test versus followup hypotheses. The table shows that no significant change occurred on the students' Overall Development score. The mean decreased from 93.8 to 92.0 suggesting that some of the gain in intercultural attitudes may have been lost once the student returns home. However, the magnitude of the change did not reach statistical significance.

No significant change was observed for either Defense/Denial or Minimization after returning home and contrary to our expectations, change in the Reversal scale at follow-up showed a surprising decline to a level comparable to pre-departure ( 3.50 vs. 3.71 vs. 3.57 respectively). The small drop previously noted in Overall Development at follow-up is due almost entirely to students' regressing on the Reversal scale. Only Acceptance/Adaptation showed a significant improvement $(\mathrm{p}=.000)$ between the post and followup assessment. As a consequence, hypotheses h1b, h2b, h3b and h4b are not supported. Only h5b, ongoing improvement in Acceptance/Adaptation was supported at follow-up. 
Table 2. Paired One-tailed t-tests of Post-test vs. Follow-up Results

\begin{tabular}{|c|c|c|c|c|c|c|c|}
\hline & \multicolumn{3}{|c|}{ Post-test Results } & \multicolumn{3}{|c|}{ Follow-up Results } & \\
\hline Hypothesis & Ave. & Range & S.D. & Ave. & Range & S.D. & $\begin{array}{l}p- \\
\text { value }\end{array}$ \\
\hline $\begin{array}{l}\mathrm{H} 1 \mathrm{~b}-\text { Overall } \\
\text { Development }\end{array}$ & 93.3 & $\begin{array}{l}72- \\
129\end{array}$ & 15.9 & 92.0 & $\begin{array}{l}59- \\
130\end{array}$ & 19.9 & .764 \\
\hline $\begin{array}{l}\mathrm{H} 2 \mathrm{~b}- \\
\text { Defense/ } \\
\text { Denial }\end{array}$ & 4.06 & $\begin{array}{l}2.9- \\
5.0\end{array}$ & .56 & 4.04 & $\begin{array}{l}2.8- \\
5.0\end{array}$ & .64 & .607 \\
\hline $\begin{array}{l}\text { H3b- } \\
\text { Reversal }\end{array}$ & 3.71 & $\begin{array}{l}2.7- \\
5.0\end{array}$ & .65 & 3.57 & $\begin{array}{l}2.3- \\
5.0\end{array}$ & .789 & 928 \\
\hline $\begin{array}{l}\mathrm{H} 4 \mathrm{~b}- \\
\text { Minimization }\end{array}$ & 2.83 & $\begin{array}{l}1.7- \\
4.3\end{array}$ & .68 & 2.82 & $\begin{array}{l}1.8- \\
4.3\end{array}$ & .76 & .610 \\
\hline $\begin{array}{l}\text { H5b - } \\
\text { Acceptance/ } \\
\text { Adaptation }\end{array}$ & 3.48 & $\begin{array}{l}2.4- \\
4.5\end{array}$ & 53 & 3.67 & $\begin{array}{l}2.9- \\
4.5\end{array}$ & .48 & .000 \\
\hline
\end{tabular}

\section{Pre-test vs. Follow-up Results}

Given the lack of significant improvement in the post-test versus follow-up results and the lower scores on the Reversal scale, and the small but statistically insignificant decline in Overall Development, the question arises as to the degree of students' overall improvement in intercultural development when measured from pre-departure to the four-month follow-up period. To answer this question a comparison of the pre-test scores and the follow-up scores (Table 3) was conducted. Results of this analysis reveal that only Minimization and Acceptance/Adaptation show a significant long-term improvement ( $\mathrm{p}=.036$ and .000 respectively). Although the overall development score shows improvement moving from 88.392.0, the change is no longer significant. Therefore, this study raises questions about the long-term benefits of study abroad on intercultural development.

Table 3. Paired One-tailed t-tests of Pre-test vs. Follow-up

\begin{tabular}{|l|c|l|l|l|l|l|l|}
\hline IDI scales & \multicolumn{3}{|l|}{ Pre-test Results } & \multicolumn{3}{l|}{ Follow-up Results } & \\
\hline & Ave. & Range & S.D. & Ave. & Range & S.D. & $\begin{array}{l}\text { p- } \\
\text { value }\end{array}$ \\
\hline $\begin{array}{l}\text { Overall } \\
\text { Development }\end{array}$ & 88.3 & $58-$ & 15.4 & 92.0 & $59-$ & 19.9 & .076 \\
& & 126 & & & 130 & & \\
\hline Defense/Denial & 4.12 & $2.8-$ & .55 & 4.04 & $2.8-$ & .64 & .809 \\
& & 5.0 & & & 5.0 & & \\
\hline Reversal & 3.50 & $2.1-$ & .742 & 3.57 & $2.3-$ & .789 & .294 \\
& & 5.0 & & & 5.0 & & \\
\hline Minimization & 2.62 & $\begin{array}{l}1.8- \\
4.0\end{array}$ & .63 & 2.82 & $1.8-$ & .76 & .030 \\
& & 4.0 & & & 4.3 & & \\
\hline Acceptance/ & 3.17 & $1.8-$ & .66 & 3.67 & $2.9-$ & .48 & .000 \\
Adaptation & & 4.5 & & & 4.5 & & \\
\hline
\end{tabular}


Richard Rexeisen, Philip Anderson, Leigh Lawton,

An $\mathbf{n}$ ub b a rd

Table 4: Test of Gender Differences at Specific Points in Time

\begin{tabular}{|l|l|l|l|l|l|l|l|}
\hline & & $\begin{array}{l}\text { Pre- } \\
\text { test }\end{array}$ & $\begin{array}{l}\text { Female } \\
\text { vs } \\
\text { Male }\end{array}$ & $\begin{array}{l}\text { Post- } \\
\text { test }\end{array}$ & $\begin{array}{l}\text { Female } \\
\text { vs } \\
\text { Male }\end{array}$ & $\begin{array}{l}\text { Follow- } \\
\text { up }\end{array}$ & $\begin{array}{l}\text { Female } \\
\text { vs } \\
\text { Male }\end{array}$ \\
\hline Overall & $\mathrm{n}$ & & $\mathrm{p}$ & & $\mathrm{p}$ & & $\mathrm{p}$ \\
\hline Female & 25 & 90.76 & 0.206 & 95.22 & 0.311 & 92.4 & 0.587 \\
\hline Male & 13 & 83.92 & & 89.57 & & 88.72 & \\
\hline DD & 25 & 4.26 & $.0130 \dagger$ & 4.22 & $.020 \dagger$ & 4.11 & 0.284 \\
\hline Female & 13 & 3.80 & & 3.78 & & 3.87 & \\
\hline Male & \multicolumn{7}{|l|}{} \\
\hline Reversal
\end{tabular}

Note: Tests comparing Females against Males are independent samples, 2-tailed tests

$\dagger$ results are significant at .05 or less.

\section{Gender Difference and Intercultural Development}

We also tested for gender difference including changes that may occur within a gender as measured at the pre, post, and follow-up periods. As shown in Table 4, females scored significantly better than the males on the Defense/ Denial scale in both the pre and post-test time periods but the difference was diminishing over the course of the experience. The results for changes in IDI scores (Table 5) provide additional evidence there may be gender differences in intercultural development. Even though women consistently scored higher on Overall Development, only men showed a significant improvement in Overall Development between the pre and post-test time period. It should be noted however that the differences between men and women diminished over time.

A question might be also asked as to why only men improved on Overall Development when only women improved on the underlying IDI scales (Minimization and Acceptance/Adaptation). How is this finding consistent with the general assumption that the IDI subscales are related to overall intercultural 
Table 5. Test of Changes within Gender Between Time Periods

\begin{tabular}{|l|l|l|l|l|l|l|l|}
\hline & & $\begin{array}{l}\text { Pre- } \\
\text { test } \\
\text { test } \\
\text { Ov-up }\end{array}$ & $\begin{array}{l}\text { Post- } \\
\text { vs } \\
\text { Post- } \\
\text { test }\end{array}$ & $\begin{array}{l}\text { Follo } \\
\text { Follow- } \\
\text { up }\end{array}$ & $\begin{array}{l}\text { Pre vs } \\
\text { Follow- } \\
\text { up }\end{array}$ \\
\hline Female & 25 & 90.76 & 95.22 & 92.40 & $.067^{*}$ & .909 & .312 \\
\hline Male & 13 & 83.92 & 89.57 & 88.72 & $.008 \dagger$ & .615 & $.063^{*}$ \\
\hline DD & & & & & & & \\
\hline Female & 25 & 4.26 & 4.22 & 4.11 & .663 & .947 & .895 \\
\hline Male & 13 & 3.80 & 3.78 & 3.87 & .580 & $.095^{*}$ & .317 \\
\hline Reversal & & & & & & & \\
\hline Female & 25 & 3.55 & 3.67 & 3.51 & .169 & .932 & .612 \\
\hline Male & 13 & 3.47 & 3.79 & 3.60 & $.092^{*}$ & .856 & .302 \\
\hline Minim & & & & & & & \\
\hline Female & 25 & 2.64 & 2.86 & 2.82 & $.021 \dagger$ & .678 & $.050 \dagger$ \\
\hline Male & 13 & 2.56 & 2.73 & 2.74 & .130 & .479 & .201 \\
\hline AA & & & & & & & \\
\hline Female & 25 & 3.15 & 3.51 & 3.75 & $.001 \dagger$ & $.001 \dagger$ & $.000 \dagger$ \\
\hline Male & 13 & 3.31 & 3.41 & 3.49 & .227 & .153 & $.078^{*}$ \\
\hline
\end{tabular}

Note: Pre to Post all are 1-tailed paired difference tests. Alternative hypothesis: Post score > Pre score

development? Given that the change in women's overall score is marginally significant it may simply be the case that sample size or related variance issues are contributing to this apparently inconsistent finding. Unfortunately sample size limitations preclude further analysis of this question. Nevertheless, both the pattern of differences and number of significant differences overall lends support for hypothesis 6.

\section{Educational Aptitude and Intercultural Development}

Assessment of the relationship between educational aptitude as measured by students' cumulative GPA and their scores on the IDI is shown in Table 6. Only two of the 15 possible correlations were significant at $\mathrm{p}=.05$ or better, and even in these two cases the correlations were very low. The pre-test score for the Reversal scale was significant with a correlation of -.371 indicating that a person with a higher GPA was prone to be oriented toward Reversal prior to 
the study abroad experience, and the follow-up score for Acceptance/Adaptation was significant with a correlation of .363 indicating that higher GPA's tended to evidence higher levels of Acceptance/Adaptation at follow-up. Overall there is very little support for Hypothesis 7.

\section{Table 6. Correlations Between GPA and IDI Scores}

\begin{tabular}{|llll|}
\hline & Pre-test & Post -test & Follow-up \\
Overall Development & -.174 & -.013 & -.059 \\
Defense/Denial & .097 & .215 & .106 \\
Reversal & $-.371{ }^{*}$ & -.101 & -.197 \\
Minimization & .062 & -.209 & -.122 \\
Acceptance/Adaptation & .152 & .298 & .363 * \\
${ }^{*}=$ Significant at $p=.05$ & & & \\
\hline
\end{tabular}

Finally we tested for an association between the students' GPA and changes in their IDI scores between the pre-test and post-test and also between the post-test and the follow-up. We did this to further examine whether there was a correlation between educational aptitude and improvement in the IDI scores. We did not find any significant correlations for any of these scales. This adds further support that there is little relationship between the students' aptitude as measured by cumulative GPA and intercultural development.

\section{Discussion}

The results of this study should both encourage and challenge those who are interested in improving the quality of study abroad programs. Like all areas of the academy, study abroad programs increasingly are being held accountable for achieving measurable learning outcomes. The current study adds to the literature by documenting that semester long, "island" programs can have a measurable, positive impact on the intercultural development of students and it addresses the question of whether study-abroad yields long-term benefits.

Our study provides strong support for the proposition that study abroad experiences have a positive immediate impact on the intercultural development of students. Not only did the Overall Development score show significant improvement by the end of the study abroad program but three of the four scales of the IDI did as well. Only the Defense/Denial scale lacked significance and on closer examination the average pre-test score for that scale (4.14) indicates that the students mostly resolved these issues prior to departure.

Of potential greater interest and concern is that this study raises questions about the long-term effects of study abroad. Although the decline in the Overall Development score from the conclusion of the program to the time of 
the follow-up study was not significant (moving from 93.3-92.0), if we ask the question, "Does cultural development improve from pre-departure to follow-up (88.3 - 92)?" the answer is inconclusive because the observed change is only marginally significant $(\mathrm{p}=.076)$. On further analysis it appears that the decline in the Overall Development score is largely due to students regressing on the Reversal scale. In other words, after returning home, many of the students came to view the country they studied in as culturally superior to their native culture. The rather large decline in the Reversal score from post to follow-up $(3.71-3.50)$ was in a direction opposite from our expectations and was large enough to prevent our concluding (pre to follow-up) that study abroad has a long-term positive impact on intercultural development. Only Acceptance/Adaptation improved during the post/follow-up period. However given that students also continue to evidence ethnocentric characteristics, the improvement in Acceptance/Adaptation must be interpreted with caution. As a consequence we want to encourage academic institutions to begin assessing how they can help their students to process their study abroad experiences better after they return to their home institution.

Figure 1 illustrates the percentage change, as opposed to absolute score, for individual students on the Overall Development scale at the end of their study abroad experience (i.e., pre-test score / post-test score). It provides a visual depiction of the intercultural development gains made by the students over the duration of the program. With few exceptions, the students experienced gains in their Overall Development scores.

\section{Figure 1.}

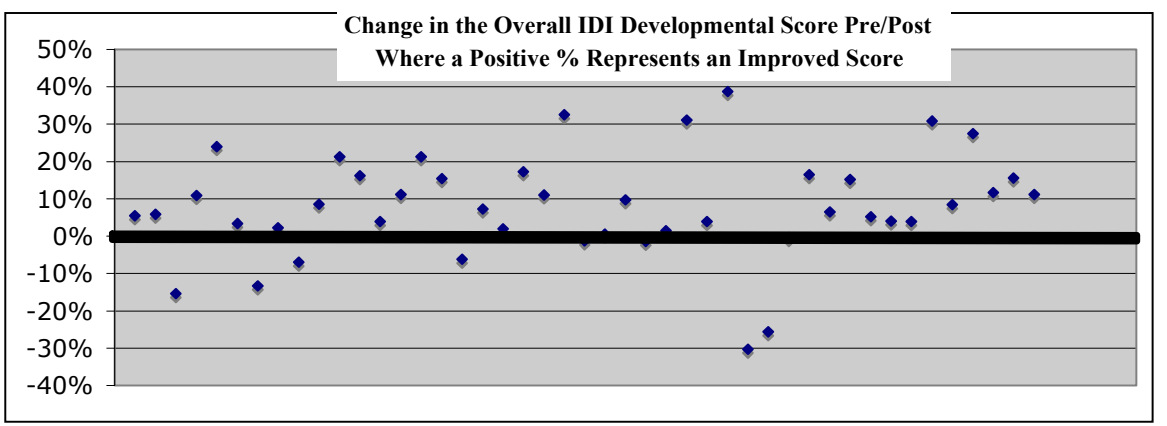

Unfortunately, we did not see the hoped-for improvement in overall intercultural development of students in the four months following the end of the study abroad experience. When comparing Figure 1 with Figure 2 you can see how some of the improvement in the Overall Development score that was recorded at 
Richard Rexeisen, Philip Anderson, Leigh Lawton,

\section{Ann Hubbard}

the end of the study abroad program (Figure 1) has diminished four months after returning home (Figure 2). There were roughly as many students with decreases in the Overall Development scores as there were students with increases.

\section{Figure 2.}

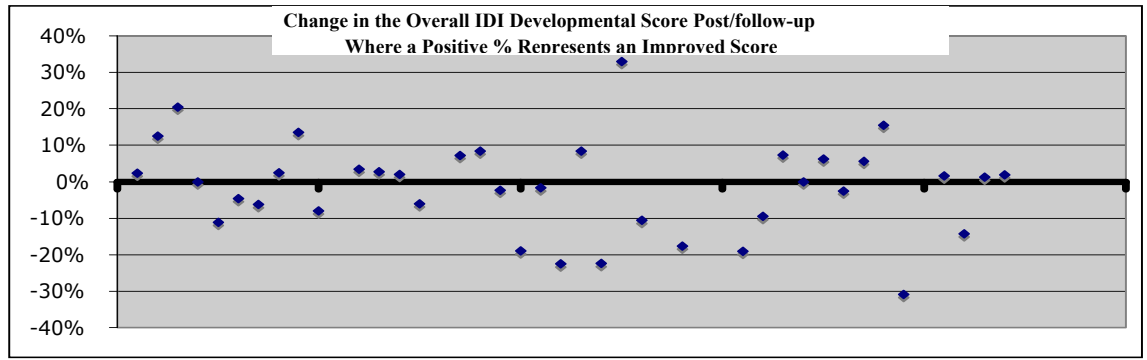

Finally, Figure 3 illustrates the Overall Developmental score changes that occurred from just prior to the study abroad experience to four-months after returning home. Although Figure 3 shows that the majority of students (69\%) had a small improvement in their Overall Development, the gain is no longer statistically significant (Table 3). This raises the question of what additional actions can be taken to help students retain the significant gains in intercultural development that are observed at the end of the study abroad program.

\section{Figure 3.}

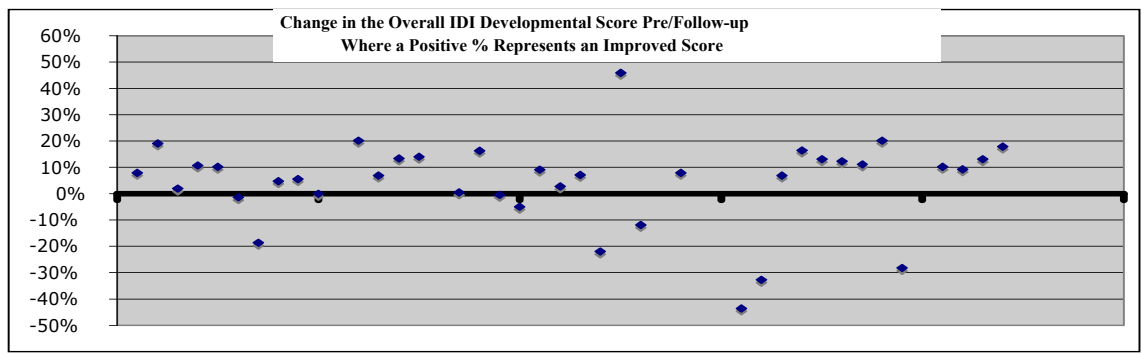

We also examined the four primary scales upon which the overall IDI development score is based. We were pleased that there was significant improvement in all of the scales (pre/post test) with the previously noted exception of Denial/Defense; and most students scored very highly on this characteristic prior to their study abroad experience. The post-test/follow-up study however only showed further improvement in Acceptance/Adaptation. When viewed 
from the perspective of the long-term educational experience, (i.e., from predeparture to follow-up) we are unable to conclude that study abroad resulted in a long-term significant overall intercultural improvement.

Educators must therefore question whether their responsibility to their students ends when the term is over or whether they should be trying to develop a longer-term if not life-long learning partnership. Should one goal of study abroad programs be to facilitate intercultural development after students return home? If so, what more can we do to build and facilitate long-term positive learning from a study abroad experience? Should study abroad students be required to take some form of "re-entry" course that facilitates the ongoing integration of intercultural experiences? Would seminars or other interventions before study abroad help students to better process and understand their experiences abroad?

Finally, this study found very little evidence that GPA is related to how students develop interculturally; at least insofar as study abroad. We did identify a relationship between gender and intercultural development but we will allow the reader to draw their own conclusion about the strength of the relationship. Hypothesis 6 was framed as a two-tailed test and given the number of potential differences that can be identified within the IDI we have concluded that further research needs to be conducted before drawing any firm conclusions.

\section{Future Research and Limitations}

The current research involves students that participated in a semester long "island" program where the students traveled and largely studied as a group. This of course raises the question of whether immersion programs, where students are more fully integrated into the foreign environment, will have a different impact on long-term intercultural development. There is also the question of whether programs of greater or shorter duration will evidence a similar erosion of developmental benefits over time. The length of time from the end of the program to follow-up is itself a limitation and future research may want to follow students over a longer period of time after their study abroad.

This research is also based on a subject pool that studied in a country with a familiar language and a comparatively similar culture (US students studying in London). The students constitute a non-probability sample where students self-select into applying to this program. Moreover the program is highly competitive; there were 89 applicants for 50 available positions. Students were admitted to the program based on interviews, letters of recommendation, personal essays and their cumulative GPA scores. The latter criterion had the effect of restricting the range of GPA scores for the study. This raises the question of 
the degree to which the results can be generalized to study abroad programs with open admission.

The current study also did not examine specific outliers, those that either benefited the most or the least from the study abroad experience. Although it may be difficult to acquire a large enough sample of outliers to permit quantitative analysis, there are a number of qualitative techniques that may enable us to develop greater insight into individual differences and to perhaps add to our knowledge base for further theory development.

Future research should also focus attention on the issue of confirming or disconfirming whether regression on the Reversal scale really does occur after students return to their home institution. Our concern is that students may tend to romanticize their study abroad experience to such an extent that they experience reversal and thereby impede their intercultural development.

The conclusions of this research are predicated on the unique characteristics of IDI instrument. While, as we noted earlier, it is grounded in theory and has been subjected to considerable psychometric testing, it still has some inherent characteristics that make assessment of hypotheses statements problematic. For example, while the Overall Development score is a continuous scale, the scales upon which it is built are independent and discontinuous. That is, a student does not have to progress through a scale (e.g., Reversal) before entering the following scales (i.e., Minimization). These unique aspects inherent in the design of the IDI required some qualifications of our assessment of the results for each of the scales. Although we are confident in our selection of the IDI instrument, future research should be done employing other empirically validated measures of intercultural development.

In general, study abroad is thought to improve intercultural awareness. There is, however, mixed evidence of whether or not changes in intercultural sensitivity can be achieved through education and training that does not involve direct contact with other cultures (Paige (1993), Pruegger and Rogers (1994), Bennett, Bennett and Allen (1999), Altschuler, Sussman, and Kachur (2003), Patterson (2006). More research is needed to compare and contrast experiential (study abroad) forms of learning with less direct (e.g., classroom) forms of education. Comparing and contrasting within this context is meant to include examining how different educational experiences might be used to support or complement each other.

Finally it should be noted the lack of significant difference for GPA may be a result of the selective admission criteria used for admission to the program. The analysis of gender differences in the current study is also limited by the relatively small sample of men that participated in the study $(\mathrm{n}=12)$. 


\section{Summary and Conclusion}

Overall this study supports that proposition that study abroad programs have a positive short-term impact on intercultural development. The long-term impact of study abroad remains, however, in question. In the absence of continued gains in the students' intercultural development, and with some evidence that erosion on the Reversal scale may be occurring, we strongly encourage academic programs give further thought to what additional resources (e.g., post study-abroad programming) might be developed to help students continue the constructive integration of their study abroad experiences. We also hope and strongly recommend that additional research be undertaken to evaluate the long-term implications of study abroad in an effort to either corroborate or refute the findings of the current study.

\section{References}

Altschuler, L., Sussman, N.M., and Kachur, E. (2003). Assessing Changes in Intercultural Sensitivity Among Physician Trainees Using the Intercultural Development Inventory. International Journal of Intercultural Relations, 27, 387-401.

Anderson, P, L. Lawton, R.J. Rexeisen and A. Hubbard, (2006) "Short-Term Study Abroad and Intercultural Sensitivity: A Pilot Study" International Journal of Intercultural Relations, 30 (4), 457-469.

Association to Advance Collegiate Schools of Business (2007) Eligibility Procedures and Accreditation Standards for Business Accreditation, pgs. 12 \& 74, http://www.aacsb.edu/accreditation/process/documents/AACSB_ STANDARDS_Revised_Jan07_Annotated.pdf

Bennett, M.J. (1986). Toward Ethnorelativism: A Developmental Model of Intercultural Sensitivity. In R.M. Paige (Ed.) Cross-cultural Orientation: New Conceptualizations and Applications. 21-70. New York, University Press of America.

Bennett, M.J. (1993). Toward Ethnorelativism: A Developmental Model of Intercultural Sensitivity. In R.M. Paige (Ed.) Education for the Intercultural Experience. 21-71. Yarmouth, ME: Intercultural Press.

Bennett, J.M., Bennett, M.J., and Allen, W. (1999). Developing Intercultural Competence in the Language Classroom. In R.M. Paige, D. Lange, and Y.A. Yershova (Eds.), Culture as the Core: Integrating Culture Into the Language Classroom, 13-46, Minneapolis, MN: University of Minnesota Press.

Bhawuk, D. and Brislin, R. (1992). The Measurement of Intercultural Sensitivity Using the Concepts of Individualism and Collectivism. International Journal of Intercultural Relations. 16 (4), 413-436. 
Corbitt, J.N. (1998). Global Awareness Profile. (Yarmouth, ME: Intercultural Press).

Davis, S. and Finney, S. (2006). A Factor analytic study of the cross-cultural adaptability inventory. Educational and Psychological Measurement, 66(2), 318-330.

DeDee, L. \& Stewart, S. (2003). The effect of student participation in international study. Journal of Professional Nursing, 19(4), 237-42.

Engle, L. and Engle, J. (2004). Assessing Language Acquisition and Intercultural Sensitivity Development in Relation to Study Abroad Program Design. Frontiers: The Interdisciplinary Journal of Study Abroad, Volume X, Fall, 219-236.

Earnest, G. W. (2003). Study abroad: A powerful new approach for developing leadership capacities. Journal of Leadership Education, 2, 2-14.

Greenholtz, J. (2000). Assessing cross-cultural competence in transnational education: The Intercultural Development Inventory. Higher Education in Europe, 25(3), 411-416.

Hammer, M.R. and Bennett, M.J. (2002). The Intercultural Development Inventory (IDI) Manual. Portland, OR: Intercultural Communication Institute.

Hammer, M. R., Bennett, M. J., \& Wiseman, R. (2003). Measuring intercultural sensitivity: The intercultural development inventory. International Journal of Intercultural Relations, 27, 421-443.

IES, Institute for Education of Students, (2002) Longitudinal Alumni Survey.

Institute of International Education. (2006). Open Doors 2006: Report on International Educational Exchange. New York, NY: IIE. http://opendoors.iienetwork.org/ file_depot/0-10000000/0-10000/3390/folder/50084/Open+Doors+2006_ FastFacts_FINAL.pdf

Kelley, C., \& Meyers, J. (1995). CCAI Cross Cultural Adaptability Inventory Manual. Minneapolis, MN: National Computer Systems, Inc.

Klak, T. and Martin, P. (2003). Do University-sponsored International Cultural Events Help Students to Appreciate Difference? International Journal of Intercultural Relations. 27, 445-465.

Landis D. and Bhagat, R.S. (1996). Handbook of Intercultural Training (2nd Ed.) Thousand Oaks, CA. Sage.

Lincoln Commission's (2005). Report on Global Competence and National Needs: One Million Students Studying Abroad. http://www.nafsa.org/_/Document/_/ lincoln_commission_report.pdf

Medina-López-Portillo, A. (2004). Intercultural Learning Assessment: The Link between Program Duration and the Development of Intercultural Sensitivity. Frontiers: The Interdisciplinary Journal of Study Abroad, Volume X, Fall, 179-199. 
Paige, R. M. (2004). Instrumentation in intercultural training. In D. Landis, J. M. Bennett, \& M. J. Bennett (Eds.), Handbook of intercultural training (3rd ed., pp. 85-128). Thousand Oaks, CA: Sage

Paige, R.M., (1993). On the Nature of Intercultural Experiences. In R.M. Paige (Ed.), Education for the Intercultural Experience. Pp. 1-19. Yarmouth, ME: International Press.

Paige, R. M., Cohen, A. D. and Shively, R. L. (2004). Assessing the impact of a strategies-based curriculum on language and culture learning abroad, Frontiers: The Interdisciplinary Journal of Study Abroad, Volume X, Fall, 253-276.

Paige, R.M., Jacobs-Cassuto, M., Yershova, Y. and DeJaeghere (2003) Assessing Intercultural Sensitivity: An Empirical Analysis of the Hammer and Bennett Intercultural Development Inventory. International Journal of Intercultural Relations, 27 (4), 467-486.

Patterson, P. (2006) Effect of Study Abroad in Intercultural Sensitivity, Unpublished Doctoral Dissertation.

Pruegger, V.J. and Rogers, T.B. (1994). Cross-cultural Sensitivity Training: Methods and Assessment. International Journal of Intercultural Relations. 18 (3), 369-387.

Rexeisen, Richard J., \& Roffler, Tara (2005). “A Longitudinal Study of the Impact of Study Abroad Experiences on Attitudes Towards the Environment." International Journal of Environmental, Cultural, Economic and Social Sustainability, 2 (1), 1-8.

Savicki, V., Downing-Burnettea, R., Hellerb, L., Binderb, F. \& Suntingerb, W. (2004). Contrasts, changes, and correlates in actual and potential intercultural adjustment. International Journal of Intercultural Relations, 28, 311-329.

Shealy, C. N. (2005). Justifying the Justification Hypothesis: ScientificHumanism, Equilintegration (EI) Theory, and the Beliefs, Events, and Values Inventory (BEVI). [Special Series]. Journal of Clinical Psychology, 61 (1), 81-106.

Shimp, T. A. and Sharma, S. (1987). Consumer ethnocentrism: construction and validation of the CETSCALE. Journal of Marketing Research, 24, August, 280-289.

The Higher Learning Commission (2007), Overview of Accreditation, Standards, 4c, p. 6, http://www.ncahlc.org/index.php?option=com_docman\&task=cat_ view\&gid $=33 \&$ Itemid $=236$ 
Richard Rexeisen, Philip Anderson, Leigh Lawton,

Ann Hubbard

Van Hoof, H., \& Verbeeten, M. (2005). Wine is for drinking, water is for washing: Student opinions about international exchange programs. Journal of Studies in International Education, 9(1), 42-61.

Vande Berg, M. (2001). The assessment of learning outcomes in study abroad. International Educator, 10 (2) 31. 